\title{
Phylogenic Studies on the Olfactory System in Vertebrates
}

\author{
Kazuyuki TANIGUCHI ${ }^{1)}$ and Kazumi TANIGUCHI ${ }^{2) *}$ \\ 1) Laboratory of Veterinary Anatomy, Faculty of Agriculture, Iwate University, 3-18-8 Ueda, Morioka, Iwate 020-8550, Japan \\ ${ }^{2)}$ Laboratory of Veterinary Anatomy, School of Veterinary Medicine, Kitasato University, 23-35-1 Higashi, Towada, Aomori 034-8628, \\ Japan
}

(Received 27 December 2013/Accepted 31 January 2014/Published online in J-STAGE 14 February 2014)

\begin{abstract}
The olfactory receptor organs and their primary centers are classified into several types. The receptor organs are divided into fishtype olfactory epithelium (OE), mammal-type OE, middle chamber epithelium (MCE), lower chamber epithelium (LCE), recess epithelium, septal olfactory organ of Masera (SO), mammal-type vomeronasal organ (VNO) and snake-type VNO. The fish-type OE is observed in flatfish and lungfish, while the mammal-type OE is observed in amphibians, reptiles, birds and mammals. The MCE and LCE are unique to Xenopus and turtles, respectively. The recess epithelium is unique to lungfish. The SO is observed only in mammals. The mammal-type VNO is widely observed in amphibians, lizards and mammals, while the snake-type VNO is unique to snakes. The VNO itself is absent in turtles and birds. The mammal-type OE, MCE, LCE and recess epithelium seem to be descendants of the fish-type OE that is derived from the putative primitive OE. The VNO may be derived from the recess epithelium or fish-type OE and differentiate into the mammal-type VNO and snake-type VNO. The primary olfactory centers are divided into mammal-type main olfactory bulbs (MOB), fish-type MOB and mammal-type accessory olfactory bulbs (AOB). The mammal-type MOB first appears in amphibians and succeeds to reptiles, birds and mammals. The fish-type MOB, which is unique to fish, may be the ancestor of the mammal-type MOB. The mammal-type AOB is observed in amphibians, lizards, snakes and mammals and may be the remnant of the fish-type MOB.
\end{abstract}

KEY WORDS: evolution, olfactory system, phylogeny, taxonomy, vertebrates.

doi: 10.1292/jvms.13-0650; J. Vet. Med. Sci. 76(6): 781-788, 2014

The concept of "phylogeny" was introduced by E. Haeckel in 1866 [9]. He presented the dendrogram dividing the organism into protists, plants and animals and tried to the process of evolution during the history of the earth amounting to about 46 hundred million years [28]. The principle of evolution is that presently living species have each evolved from earlier, but not contemporary species [32]. On the other hand, the olfaction is the earliest sensation in appearance during phylogeny. The olfaction plays the leading role in the development of the nervous system in mammals during the process of evolution. In this context, the phylogenic study on the olfaction of vertebrates is the most useful tool for the best understanding of the origin and evolution of the nervous system in mammals.

\section{ORIGIN AND EVOLUTION OF THE OLFACTORY SYSTEM IN VERTEBRATES}

Primitive animals first appeared in the water. They detected the odoriferous molecules dissolved in the water by the olfactory epithelium (OE) as the olfactory stimuli [49]. The OE seems to be present from the beginning of the evolu-

\footnotetext{
*Correspondence to: TAniguchi, K., Laboratory of Veterinary Anatomy, School of Veterinary Medicine, Kitasato University, 23-35-1 Higashi, Towada, Aomori 034-8628, Japan.

e-mail: taniguch@vmas.kitasato-u.ac.jp

(C)2014 The Japanese Society of Veterinary Science

This is an open-access article distributed under the terms of the Creative Commons Attribution Non-Commercial No Derivatives (by-nc-nd) License $<$ http://creativecommons.org/licenses/by-nc-nd/3.0/>.
}

tion of their olfactory system [44]. Later, they invaded the land and were forced to detect the odoriferous molecules in the air [12]. However, the transition of their life style from in the water to on the land did not alter the functional mechanisms of the OE: the OE could detect only the odoriferous molecules dissolved in the liquid. This situation induced the development of the associated glands (Bowman's glands) in the OE to dissolve the odoriferous molecules in their secretion to be perceived by the $\mathrm{OE}$ as the olfactory stimuli $[2,4$, $7,29,34]$. The absence of the Bowman's glands in aquatic animals implies that they do not need associated glands of the OE to detect odoriferous molecules as olfactory stimuli because these molecules are already dissolved in the water.

On the other hand, the vomeronasal organ (VNO) was derived from the primitive $\mathrm{OE}$ (Fig. 1); and it seemed to be differentiated as the pheromone receptor $[3,26,46]$. The time and process of the differentiation of the VNO from the $\mathrm{OE}$ is an important problem in the phylogeny of olfaction in vertebrates [42]. This problem will later be discussed in this review.

\section{MAMMALIAN OLFACTORY SYSTEM}

The olfactory system in mammals is divided into two distinct systems, the main and accessory olfactory systems (Fig. 2). The main olfactory system consists of the main olfactory bulb (MOB) as the primary center and the $\mathrm{OE}$ as the receptor [33]. On the other hand, the accessory olfactory system consists of the accessory olfactory bulb (AOB) as the primary center and the VNO and the septal olfactory organ of Masera (SO) as receptors [1, 10, 17, 19, 38]. The MOB 


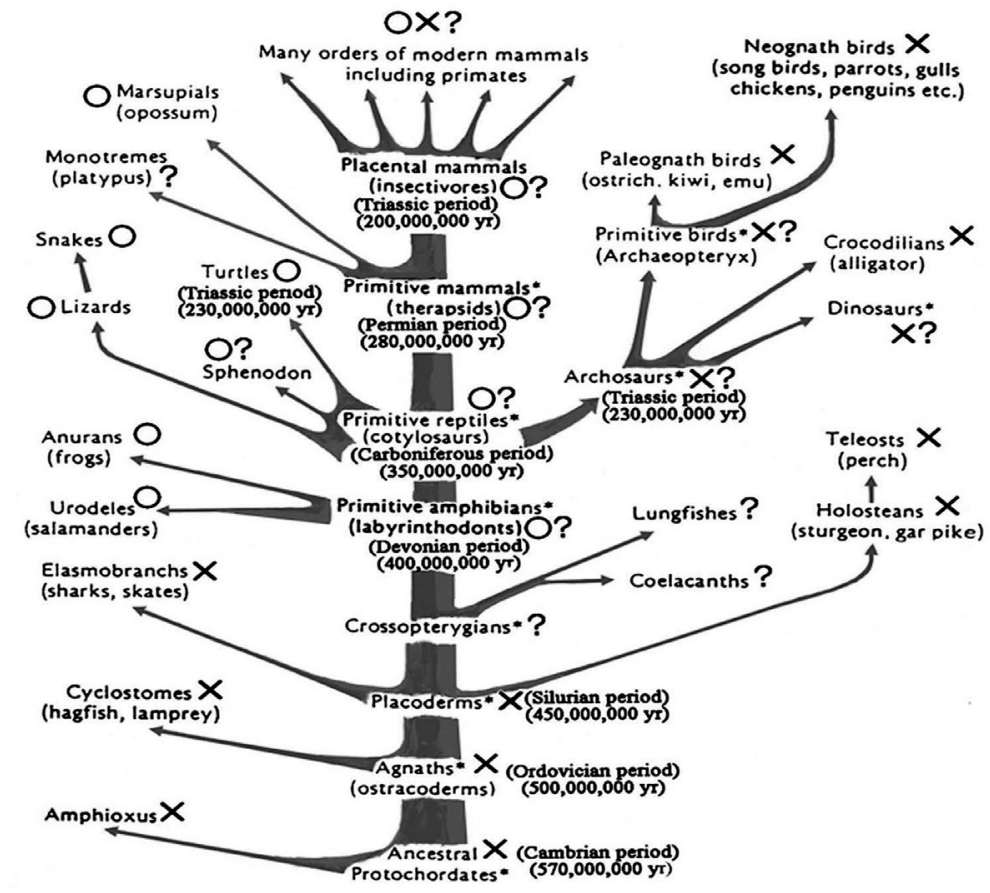

Fig. 1. Schematic drawings of the phylogenic tree of the vertebrates showing the presence $(\mathrm{O})$ or absence $(\mathrm{X})$ of the vomeronasal organ. Modified after Sarnat and Netsky (1974) [Ref. 32]. Asterisks (*) indicate extinct taxa.

consists of six layers, olfactory nerve layer, glomerular layer, external plexiform layer, mitral cell layer, internal plexiform layer and granule cell layer. The AOB also consists of six layers with a few differences from the MOB, the vomeronasal nerve layer, glomerular layer, mitral/tufted cell layer, plexiform layer, lateral olfactory tract and granule cell layer (Fig. 3).

As for the cytoarchitecture, output neurons of the MOB are mitral cells and tufted cells, while these cells are not distinguished in the AOB and called as mitral/tufted cells [36]. In addition, various kinds of short axon cells are observed in both MOB and $\mathrm{AOB}$ and play significant roles as interneurons [21, 27]. We call these types of MOB and AOB the mammal-type MOB and mammal-type AOB in this review. The glomerular layers of the MOB and AOB consists of many glomeruli. The glomeruli are the sites of synapse formation between axons of the receptor cells of the $\mathrm{OE}$ or VNO and dendrites of the output neurons of the $\mathrm{MOB}$ or AOB. The axons of the output neurons of the MOB run in the lateral olfactory tract. Histochemical properties of individual glomerulus are different with each other in both MOB and AOB. Each glomerulus shows distinct expression patterns in the kind and amount of glycoconjugates from the other. These findings are revealed by comparative studies on the immunohistochemical characteristics and lectin binding patterns among glomeruli in the MOB and $\mathrm{AOB}$. In addition, these findings may suggest that there are functional assignments among glomeruli.

The OE is distributed on the dorsocaudal aspect of the

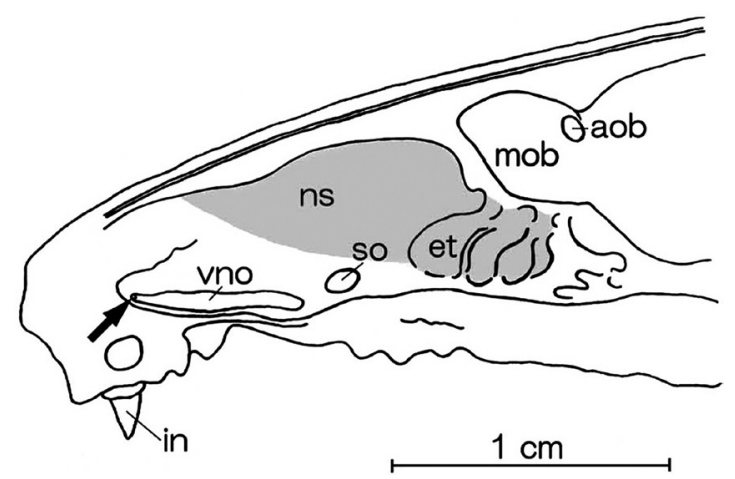

Fig. 2. Schematic drawings of the parasagittal section of the nasal cavity in the rat. aob: accessory olfactory bulb, et: endoturbinates, in: incisor, mob: main olfactory bulb, ns: nasal septum, so: septal olfactory organ of Masera, vno: vomeronasal organ. An arrow indicates the opening of the vomeronasal organ. The shadow represents the distribution of the olfactory epithelium.

nasal septum and roof of the nasal cavity, and on the endoturbinates. The OE is ciliated and consists of olfactory, supporting and basal cells. We call this type of OE the mammal-type $\mathrm{OE}$ in this review.

The VNO is a tubular structure situated at the base of the nasal septum and ends blindly. Anteriorly, the VNO opens into the nasal cavity with the small pore as in rodents or communicates with the oral cavity via the incisive duct as in 
ruminants, horses and carnivores [40]. However, some marine animals, such as cetaceans and manatees [18], and the higher primates lack the VON completely and are provided with only the main olfactory system. In mammals provided with the VNO, medial and lateral walls of the lumen of the VNO are covered with the vomeronasal sensory epithelium (VSE) and non-sensory epithelium (NSE), respectively. The VSE is microvillous, but the NSE is ciliated. The VSE consists of vomeronasal sensory, supporting and basal cells [39, 40]. We call this type of VNO the mammal-type VNO.

Functional mechanisms of the VNO are different among mammalian species and depend whether it communicates with the nasal or oral cavity. As the secondary palate is completed in mammals [12], the nasal and oral cavities are separated by the hard and soft palates and communicate with each other by the incisive duct. The incisive duct is thought to be the rudiment of the internal nares (choanae) and opens at the base of the incisive papilla on the roof of the oral cavity. When the VNO communicates with the nasal cavity, odoriferous molecules are uptaken into the VNO by the mechanism of the vomeronasal pump of the VNO $[10,20]$. On the other hand, when the VNO communicates with the oral cavity through the incisive duct, odoriferous molecules are uptaken into the VNO with the inspirate by a unique mammalian behavior, the flehmen [3]. In such a case, a part of odoriferous molecules are sent into the nasal cavity through the incisive duct.

The SO is a small patch of the epithelium similar to the $\mathrm{OE}$ and situated on the ventrocaudal aspect of the nasal septum [17, 38]. It is embryologically derived from the developing OE in mammals. Although the SO is unique to mammals, its functional or phylogenetic significance is not fully understood at present.

\section{AVIAN OLFACTORY SYSTEM}

Avian olfactory system consists of the MOB and the OE, and lacks the accessory olfactory system. Because of the avian behavior of the flight, the olfactory system is in general not well-developed in birds. Since the secondary palate is incomplete and lacks the soft palate in birds, the nasal and oral cavities communicate with each other by the slit-like palatal fissure in the midline of the palate [12]. The OE consists of olfactory, supporting and basal cells similar to that in mammals, but it occupies only a small area of the nasal cavity [14]. As the olfactory cells in the OE are rather small in number in birds than in mammals, the $\mathrm{OE}$ is lower in height in birds than in mammals. The olfactory bulb is represented only by the MOB and lacks the AOB. The lamellar structure of the avian MOB is almost the same as in mammals. Six layers are recognized in birds as in mammals in the MOB. Cytoarchitecture of the avian MOB is almost the same as in mammals. Right and left MOBs are frequently fused in the midline $[14,48]$. In conclusion, the avian olfactory system consists solely of the main olfactory system composed of mammal-type MOB and mammal-type OE.

\section{REPTILIAN OLFACTORY SYSTEM}

Reptiles constitute the paraphyletic group in taxonomy and have no common ancestors in phylogeny. Therefore, we adopt three living reptilian groups, lizards, snakes and turtles, as reptilian representatives in this review (Figs. 4 and 5).

In reptiles, generally, the secondary palate is incomplete, except for crocodilians, and the nasal and oral cavities communicate with each other with varying degrees. The development of the VNO is also various among reptilian species.

In lizards, the VNO is isolated from the nasal cavity and opens into the oral cavity via the vomeronasal duct at the anterior tip and ends blindly posteriorly. The VNO in lizards corresponds to mammal-type VNO. The ventral wall of the VNO protrudes into its crescent lumen to form the mushroom body. Although the mushroom body is covered with the nonsensory epithelium, the rest of the wall of the lumen of the VNO is mostly covered with the VSE $[16,30]$. Odoriferous molecules are uptaken into the VNO by the action of the facial bones, jaws and the head itself [10]. The VSE projects to the AOB whose cytoarchitecture is almost the same as in mammals and corresponds to the mammal-type AOB. On the other hand, the nasal cavity of lizards is a single rounded chamber without the nasal concha and mostly covered with the mammal-type OE. The OE projects to the MOB whose cytoarchitecture almost corresponds to mammal-type MOB.

In snakes, the VNO opens into the oral cavity in a similar manner to lizards. The mushroom body is also equipped to the VNO as in lizards. The distribution of the VSE and non-sensory epithelium is also similar to lizards [37]. Histological structure of the VSE, however, is unique to snakes and shows no resemblance to the other vertebrate species. Therefore, we call the VNO in snakes the snake-type VNO. The supporting cells are situated in the apical region of the VSE and arranged in a single row [13]. The supporting cell layer is demarcated by the connective tissue containing vessels from the underlying region of sensory cells and basal cells. The VSE projects to the AOB as in lizards and mammals. The cytoarchitecture of the AOB corresponds to mammal-type AOB. On the other hand, functional mechanism of the VNO is unique to snakes. Odoriferous molecules are attached to the sticky tips of the bifurcated tongue and sent into the VON by the tongue-flicking $[6,10]$. In addition, the nasal cavity becomes complicated in snakes and protrudes the single nasal concha from its lateral wall. The nasal concha is almost entirely covered with the mammaltype OE. The dorsomedial and the most of the dorsolateral wall of the nasal cavity is covered with the OE, while the ventral wall and a part of the dorsolateral wall of the nasal cavity are covered with the non-sensory epithelium. The projection pattern of the $\mathrm{OE}$ to the MOB is almost the same as in lizards and mammals; and the MOB also shows the similar cytoarchitecture to lizards and mammals and corresponds to the mammal-type MOB [15]. That is, the MOB in snakes corresponds to mammal-type MOB.

In turtles, the nasal cavity is a simple chamber devoid of the nasal conchae and divided into upper and lower chambers [8]. These chambers are almost the same in size and 


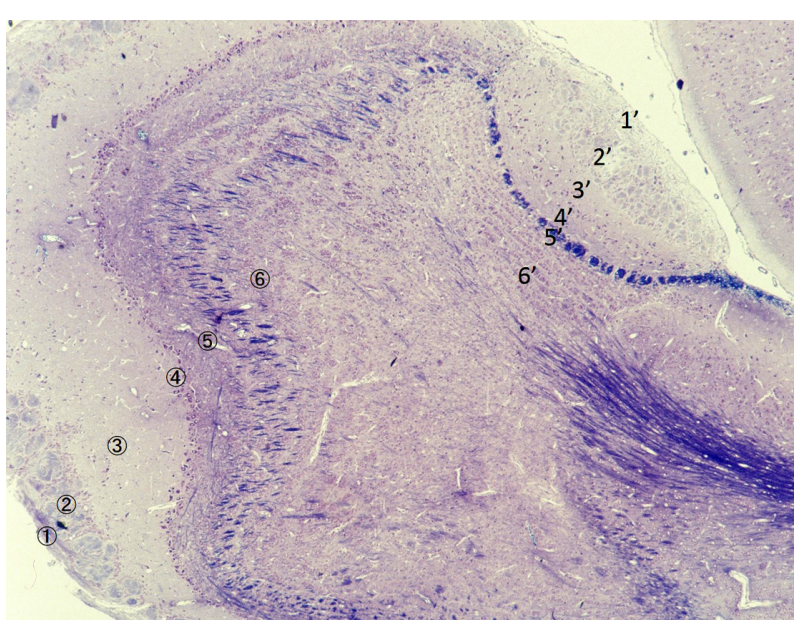

Fig. 3. Lamellar structure of the main (MOB) and accessory olfactory bulb (AOB) in the rat. (1) (6): $\mathrm{MOB}, 1$ ' 6': AOB, (1): olfactory nerve layer, (2): glomerular layer, (3): external plexiform layer, (4): mitral cell layer, (5): internal plexiform layer, (6): granule cell layer, $1^{\prime}$ : vomeronasal nerve layer, $2^{\prime}$ : glomerular layer, $3^{\prime}$ : mitral/tufted cell layer, $4^{\prime}$ : plexiform layer, $5^{\prime}$ : lateral olfactory tract, $6^{\prime}$ : granule cell layer.

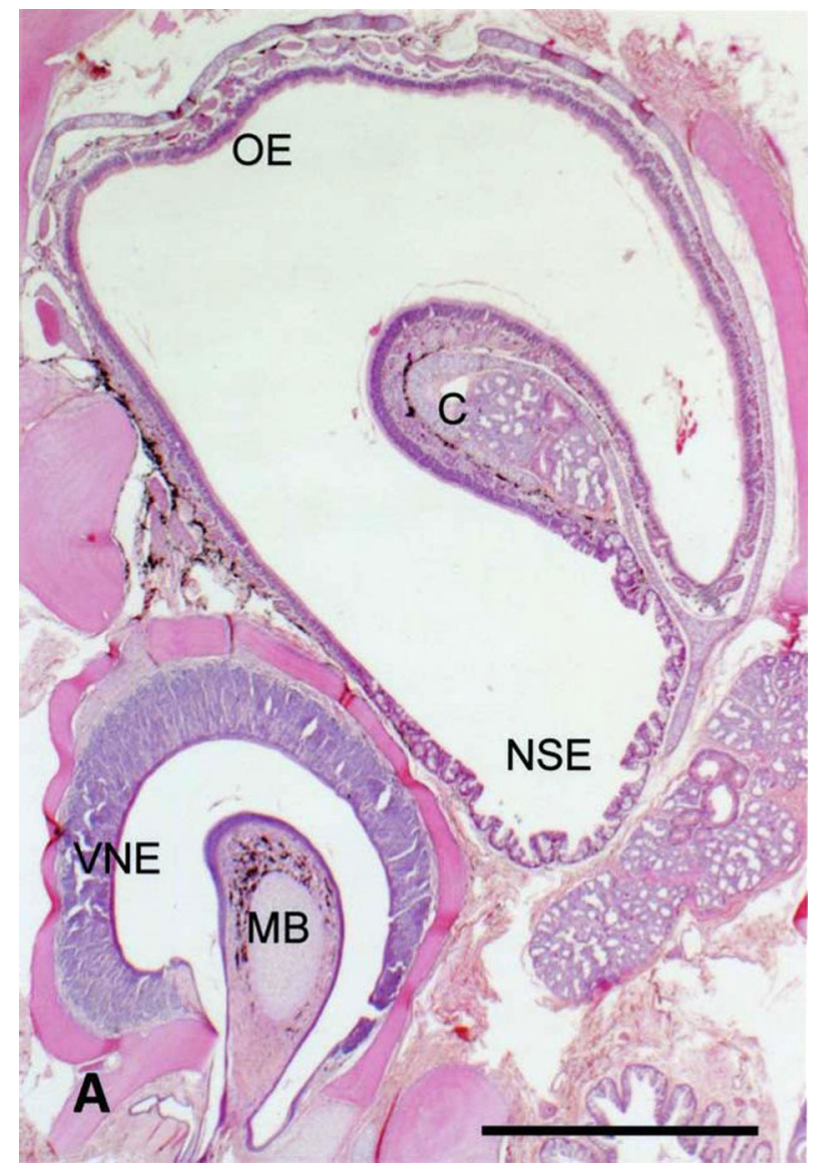

Fig. 5. Frontal section of the nasal region in the snake. C: nasal concha, MB: mushroom body, NSE: non-sensory epithelium, OE: olfactory epithelium, VNE: vomeronasal sensory epithelium. $\mathrm{Bar}=500 \mu \mathrm{m}$.

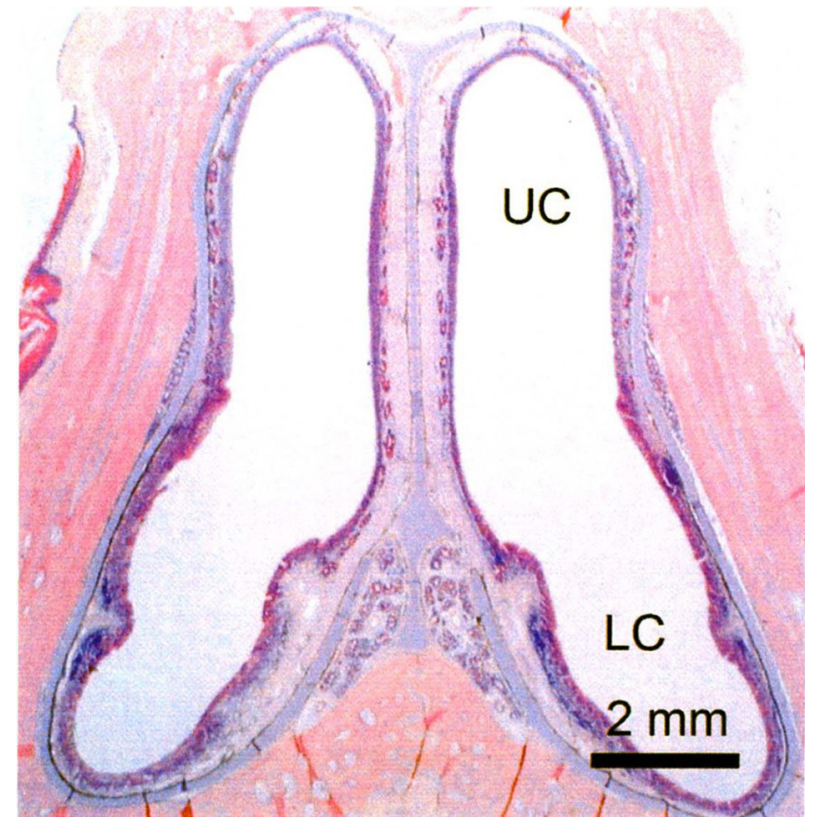

Fig. 4. Transverse section of the nasal cavity in the turtle. LC: lower chamber, UC: upper chamber.

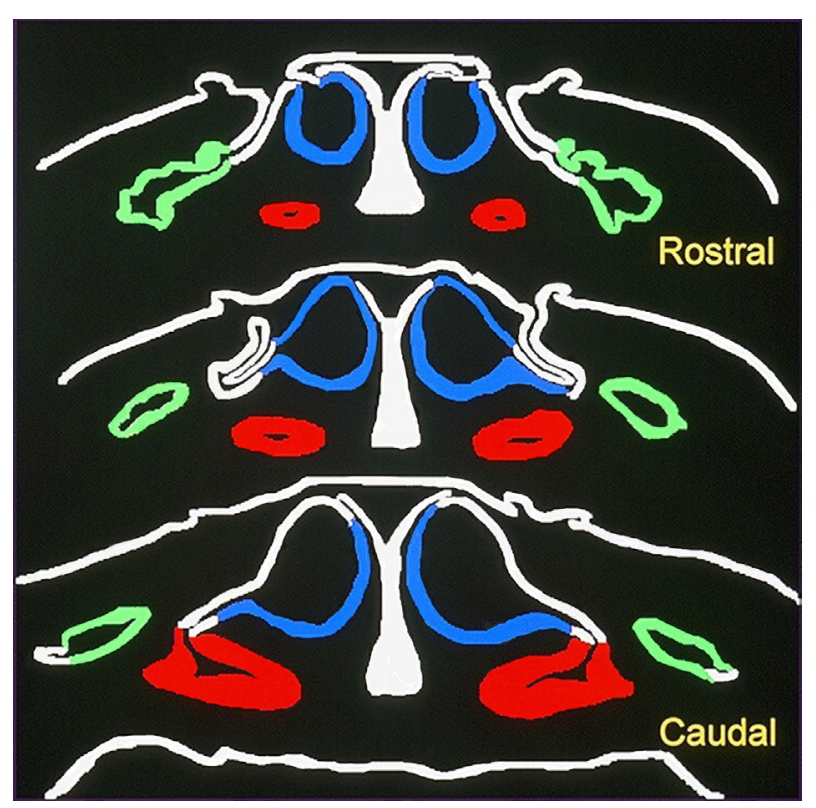

Fig. 6. Three nasal chambers in Xenopus laevis. Blue: upper chamber lined with the olfactory epithelium. Green: middle chamber lined with the middle chamber epithelium. Red: lower chamber lined with the vomeronasal sensory epithelium.

demarcated by the non-sensory epithelium at their border; and both lead to the choanae. The upper chamber is mostly covered with the OE containing ciliated and microvillous olfactory cells as in mammal-type $\mathrm{OE}$ and equipped with the associated glands, but the lower chamber is covered with a 
kind of sensory epithelium similar to the VSE and devoid of the associated glands. We call this epithelium the lower chamber epithelium (LCE) in this review. The presence or absence of the associated glands in the epithelium in upper or lower chambers may suggest that the upper and lower chambers take charge of the olfaction in air and in water, respectively. Lectin binding patterns are different between upper and lower chambers, but $G$ protein coupling to the olfactory receptors is commonly expressed in both upper and lower chambers. Since the VNO in general ends blindly at its caudal extremity and lacks $\mathrm{G}$ protein coupling to the olfactory receptors, the lower chamber in turtles does not correspond to the VNO. In addition, the olfactory bulb is divided into two almost equivalent halves. The upper half receives the projection from the sensory epithelium in the lower chamber, while the lower half receives the projection from the $\mathrm{OE}$ in the upper chamber. The cytoarchitecture of the olfactory bulb is almost the same in both upper and lower halves and corresponds to mammal-type MOB. These findings suggest that turtles lack the accessory olfactory system and that sensory epithelium in the lower chamber reminds us the fish-type OE described later in this review.

\section{AMPHIBIAN OLFACTORY SYSTEM}

Living amphibians consist of three groups, anurans, urodeles and apodans. Since apodans are regarded as retrogressive animals and contain only a few species [12], we adopt anurans and urodeles as the representative of living amphibians.

In anurans, the nasal cavity is divided into upper, middle and lower chambers (Fig. 6). In general, upper, middle and lower chambers are lined with the OE, the non-sensory epithelium and the VSE, respectively [5]. The OE in anurans corresponds to mammal-type OE, and the VSE is a component of mammal-type VNO. The OE and the VSE project to mammal-type MOB and mammal-type AOB, respectively. Therefore, the main and accessory olfactory systems are recognized as usual in anurans. In the African clawed frog, Xenopus laevis, however, the middle chamber is lined with a sensory epithelium different from both OE and VSE [25, 35]. We call this epithelium temporarily the middle chamber epithelium (MCE) in this review. The MCE contains ciliated and microvillous sensory cells, ciliated and microvillous supporting cells, and basal cells and lacks the associated glands, while the OE contains ciliated olfactory cells, microvillous supporting cells and basal cells, is equipped with well-developed associated glands as in terrestrial animals and corresponds to mammal-type OE. In Xenopus, the MOB is divided into upper and lower parts, each receiving projections from the $\mathrm{OE}$ and the MCE, respectively. These findings suggest that the main olfactory system in Xenopus is subdivided into two olfactory pathways, that is, from the OE to the upper part of the MOB and from the MCE to the lower part of the MOB [11, 31, 41]. Although lectin binding patterns are different between upper and lower parts of the MOB, the cytoarchitecture is almost common in the whole MOB and corresponds to that of mammal-type MOB. The VSE in the lower chamber projects to the AOB situated dorsocaudally to the MOB as usual. The AOB in Xenopus corresponds to mammal-type AOB. These findings may suggest that the $\mathrm{OE}$ and the MCE take charge of the olfaction in the air and water, respectively.

In urodeles, the nasal cavity is rather primitive and consists of a broad single chamber. The VNO is recognized as a lateral diverticulum of the nasal cavity. The main chamber of the nasal cavity, except for the diverticulum, is lined with the OE, and the lateral diverticulum is lined with the VSE similar to that observed in the mammal-type VNO. The OE corresponds to mammal-type OE. The OE and the VSE project to the MOB and the AOB, respectively, as usual. The cytoarchitectures in the $\mathrm{MOB}$ and $\mathrm{AOB}$ are still primitive, but resembles those of mammal-type MOB and mammaltype AOB.

\section{FISH OLFACTORY SYSTEM}

Fish constitute the most dominant group in species and individuals in vertebrates [12]. Fish olfactory system is generally believed to be composed solely of the main olfactory system and lacks the VNO and the AOB. The nasal cavity is displaced by the nasal pit in fish. The nasal pit is a tubular structure, opens to the exterior via anterior and posterior pores and has no communication with the oral cavity. Many olfactory lamellae are observed in the nasal pit and equipped with the OE. The OE is not a sheet of the epithelium as in mammals and takes the forms of islets separated from the neighboring $\mathrm{OE}$ by the non-sensory epithelium. As our understandings about fish olfactory system are restricted to rather few species, we adopt flatfish and lungfish as the representative of living fish. Flatfish and lungfish belong to teleosts and dipnoans, respectively.

In flatfish, the OE contains ciliated and microvillous olfactory cells, a special type of sensory cells, i.e., crypt cells, ciliated and microvillous supporting cells, and basal cells and lacks the associated glands $[22,45,47]$. We call this type of the OR the fish-type OE in this review. The OE projects to the primitive olfactory bulb, where mitral and tufted cells cannot be distinguished from each other and called collectively as mitral/tufted cells. This olfactory bulb in fish may correspond to mammal-type $\mathrm{AOB}$, and we call this olfactory bulb the fish-type MOB in this review.

In lungfish, many olfactory lamellae are suspended from the roof of the nasal pit and covered with islets of the fishtype $\mathrm{OE}$ separated from neighboring $\mathrm{OE}$ by the sensory epithelium, although the lungfish OE is devoid of crypt cells and different in the strict sense of the definition from that in flatfish [43]. The OE projects to the primitive olfactory bulb as in flatfish, i.e., the fish-type MOB. In addition, at the base of each lamella near the roof of the nasal pit, the covering of the lamella becomes depressed and form recesses (Fig. 7). These recesses are lined with a sensory epithelium unique to the recesses in lungfish $[23,24]$. We call this epithelium temporarily the recess epithelium in this review. The recess epithelium contains microvillous sensory cells, microvillous supporting cells and basal cells. The organization of the 


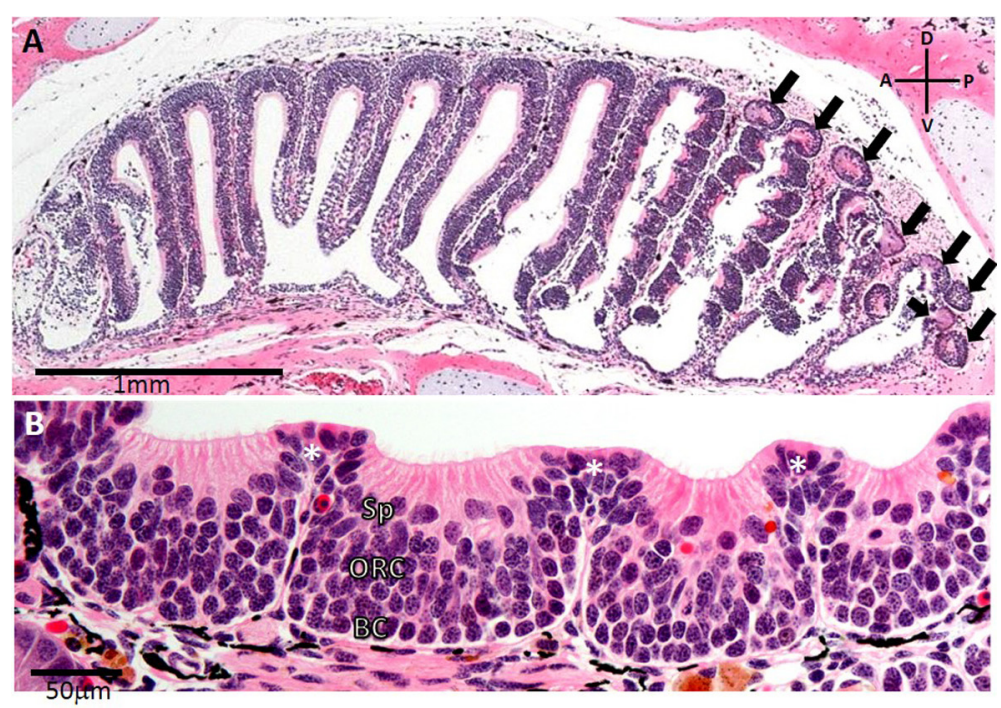

Fig. 7. The olfactory organ of lungfish stained with HE. (A) Sagittal section of the nasal sac of the lungfish showing many lamellae hanging from the roof. Recesses (arrows) are observed at the base of the lamellae and lined with the recess epithelium. A: anterior, D: dorsal, P: posterior, V: ventral. (B) The lamellar olfactory epithelium covering the lamellae. Neighboring lamellar olfactory epithelia are separated by non-sensory epithelium (asterisk). BC: basal cell, ORC: olfactory receptor cell, SP: supporting cell.

\section{Phylogeny of Olfactory Receptors}

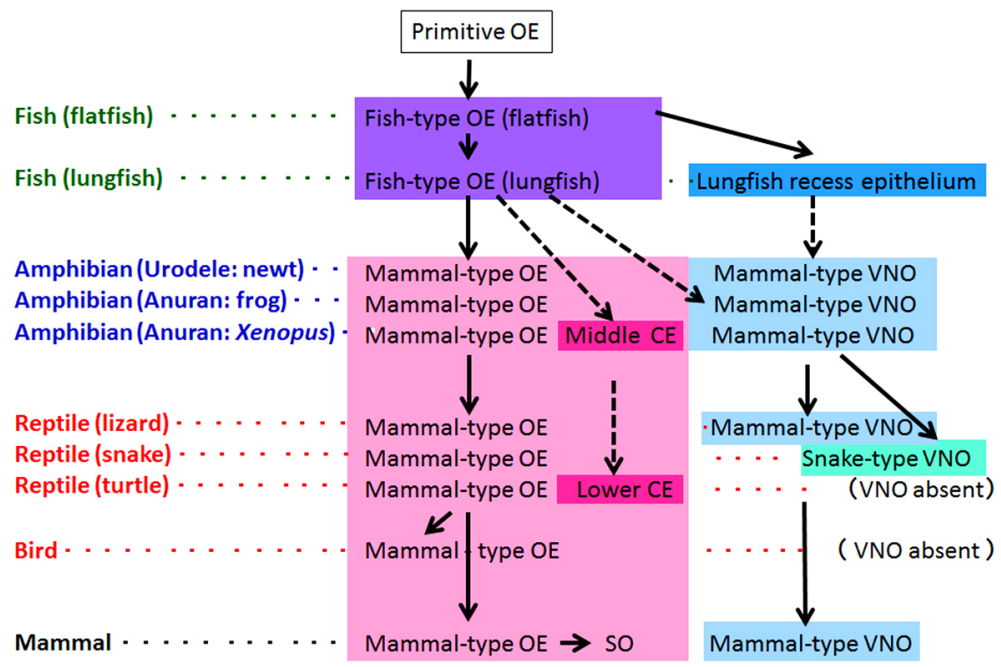

Fig. 8. Phylogeny of the olfactory receptor organs in vertebrates. CE: chamber epithelium, OE: olfactory epithelium, SO: septal olfactory organ of Masera, VNO: vomeronasal organ.

recess epithelium reminds us the VSE in terrestrial animals. The recess epithelium may be the primordial VSE, but is situated sporadically at the base of each olfactory lamella. On the other hand, as the VSE is a single sheet of the epithelium, it is unclear how the spotted recess epithelia assemble to form a single sheet of the VSE through any process. The truth has not yet come out.

\section{CONCLUSION}

In this review, we classified the olfactory receptor organs and their primary centers into several types (Fig. 8). 
The olfactory receptor organs are divided into fish-type OE, mammal-type OE, MCE, LCE, recess epithelium, mammal-type VNO, snake-type VNO and SO. The fish-type OE is observed in both flatfish and lungfish. The mammal-type OE is dominant and observed in amphibians, reptiles, birds and mammals. The MCE is unique to Xenopus. The LCE is also unique to turtles. The SO is observed only in mammals. The recess epithelium is unique to lungfish. The mammaltype VNO is dominant and observed in amphibians, lizards and mammals. The snake-type VNO is unique to snakes. The VNO itself is absent in turtles and birds.

On the other hand, the primary olfactory centers are divided into mammal-type MOB, mammal-type AOB and fish-type MOB. The mammal-type MOB is dominant and observed in amphibians, reptiles, birds and mammals. The mammal-type AOB is observed in amphibians, lizards, snakes and mammals, but absent in animals devoid of the VNO. The fish-type MOB is unique to fish.

Phylogenetically, the fish-type OE seems to be derived from the putative primitive OE. The mammal-type OE, MCE, LCE and recess epithelium seem to be descendants of the fish-type OE. The VNO may be derived from the recess epithelium or fish-type OE and differentiate into the mammal-type VNO and snake-type VNO. The mammal-type MOB first appears in amphibians and succeeds to reptiles, birds and mammals. The fish-type MOB may be the ancestor of the mammal-type MOB, while the mammal-type AOB may be the remnant of the fish-type MOB.

\section{REFERENCES}

1. Barber, P. C. and Raisman, G. 1974. An autoradiographic investigation of the projection of the vomeronasal organ to the accessory olfactory bulb in the house mouse. Brain Res. 81: 21-30. [Medline] [CrossRef]

2. Dawley, E. M. and Bass, A. H. 1988. Organization of the vomeronasal organ in a plethodontid salamander. J. Morphol. 198: 243-255. [CrossRef]

3. Estes, R. D. 1972. The role of the vomeronasal organ in mammalian reproduction. Mammalia 36: 315-341. [CrossRef]

4. Farbman, A. I. and Gesteland, R. C. 1974. Fine structure of olfactory epithelium in the mud puppy, Necturus maculosus. Am. J. Anat. 139: 227-243. [Medline] [CrossRef]

5. Franceschini, F., Sbarbati, A. and Zancanaro, C. 1991. The vomeronasal organ in the frog, Rana esculenta. An electron microscopy study. J. Submicrosc. Cytol. Pathol. 23: 221-231. [Medline]

6. Gillingham, J. C. and Clark, D. L. 1981. Snake tongue-flicking: transfer mechanics to Jacobson's organ. Can. J. Zool. 59: 1651-1657. [CrossRef]

7. Graziadei, P. P. C. and Graziadei, G. A. M. 1976. Olfactory epithelium of Necturus maculosus and Ambystoma tigrinum. J. Neurocytol. 5: 11-32. [Medline] [CrossRef]

8. Graziadei, P. P. C. and Tucker, D. 1970. Vomeronasal receptors in turtles. Z. Zellforsch. 105: 498-514. [Medline] [CrossRef]

9. Haeckel, E. Genelelle Morphologie der Organismen: Allgemeine Grundzüge der organischen Formen-Wissenschaft, mechanish begründet durch die von Charles Darwin reformirte Descendenz-Theorie. GeorgReimer, Berlin (in German).

10. Halpern, M. 1987. The organization and function of the vom- eronasal system. Annu. Rev. Neurosci. 10: 325-362. [Medline] [CrossRef]

11. Hofmann, M. H. and Meyer, D. L. 1991. Functional subdivisions of the olfactory system correlate with lectin-binding properties in Xenopus. Brain Res. 564: 344-347. [Medline] [CrossRef]

12. Kent, G.C. and Carr, R.K. 2001. Comparative Anatomy of the Vertebrates, 9th ed., McGraw-Hill, Boston.

13. Kondoh, D., Yamamoto, Y., Nakamuta, N., Taniguchi, K. and Taniguchi, K. 2010. Lectin histochemical studies on the olfactory epithelium and vomeronasal organ in the Japanese striped snake, Elaphe quadrivirgata. J. Morphol. 271: 1197-1203. [Medline] [CrossRef]

14. Kondoh, D., Nashimoto, M., Kanayama, S., Nakamuta, N. and Taniguchi, K. 2011. Ultrastructural and histochemical properties of the olfactory system in the Japanese jungle crow, Corvus macrorhynchos. J. Vet. Med. Sci. 73: 1007-1014. [Medline] [CrossRef]

15. Kondoh, D., Wada, A., Endo, D., Nakamuta, N. and Taniguchi, K. 2013. Histological and lectin histochemical studies on the main and accessory bulbs in the Japanese striped snake, Elaphe quadrivirgata. J. Vet. Med. Sci. 75: 567-574. [Medline] [CrossRef]

16. Kratzing, J. E. 1975. The fine structure of the olfactory and vomeronasal organs of a lizard (Tiliqua scincoides scincoides). Cell Tissue Res. 156: 239-252. [Medline] [CrossRef]

17. Kratzing, J. E. 1978. The olfactory apparatus of the bandicoot (Isoodon macrourus): fine structure and presence of a septal olfactory organ. J. Anat. 125: 601-613. [Medline]

18. Mackay-Sim, A., Duvall, D. and Graves, B. M. 1985. The West Indian manatee (Trichechus manatus) lacks a vomeronasal organ. Brain Behav. Evol. 27: 186-194. [Medline] [CrossRef]

19. Marshall, D. A. and Maruniak, J. A. 1986. Masera's organ responds to odorants. Brain Res. 366: 329-332. [Medline] [CrossRef]

20. Meredith, M., Marques, D. M., O'Connell, R. O. and Stern, F. L. 1980. Vomeronasal pump: significance for male hamster sexual behavior. Science 207: 1224-1226. [Medline] [CrossRef]

21. Nakajima, T., Okamura, M., Ogawa, K. and Taniguchi, K. 1996. Immunohistochemical and enzyme histochemical characteristics of short axon cells in the olfactory bulb of the golden hamster. $J$. Vet. Med. Sci. 58: 903-908. [Medline] [CrossRef]

22. Nakamuta, S., Nakamuta, N. and Taniguchi, K. 2010. Ultrastructure of the olfactory epithelium in a flatfish, barfin flounder (Verasper moseri). J. Vet. Med. Sci. 72: 801-804. [Medline] [CrossRef]

23. Nakamuta, S., Nakamuta, N., Taniguchi, K. and Taniguchi, K. 2012. Histological and ultrastructural characteristics of the primordial vomeronasal organ in lungfish. Anat. Rec. 295: 481-491. [Medline] [CrossRef]

24. Nakamuta, S., Nakamuta, N., Taniguchi, K. and Taniguchi, K. 2013. Localization of the primordial vomeronasal organ and its relationship to the associated gland in lungfish. J. Anat. 222: 481-485. [Medline] [CrossRef]

25. Oikawa, T., Suzuki, K., Saito, T. R., Takahashi, K. W. and Taniguchi, K. 1998. Fine structure of three types of olfactory organs in Xenopus laevis. Anat. Rec. 252: 301-310. [Medline] [CrossRef]

26. Powers, J. B. and Winans, S. S. 1975. Vomeronasal organ: critical role in mediating sexual behavior of the male hamster. Science 187: 961-963. [Medline] [CrossRef]

27. Price, J. L. and Powell, T. P. 1970. The mitral and short axon cells of the olfactory bulb. J. Cell Sci. 7: 631-651. [Medline]

28. Romer, A. S. 1970. The Vertebrate Body, 4th ed., Saunders, 
Philadelphia.

29. Saito, S., Matsui, T., Kobayashi, N., Wakisaka, H., Mominoki, K., Matsuda, S. and Taniguchi, K. 2003. Lectin histochemical study on the olfactory organ of the newt, Cynopus pyrrhogaster, revealed heterogenous mucous environments in a single nasal cavity. Anat. Embryol. (Berl.) 206: 349-356. [Medline]

30. Saito, S., Oikawa, T., Taniguchi, K. and Taniguchi, K. 2010. Fine structure of the vomeronasal organ in the grass lizard, Takydromus tachydromoides. Tissue Cell 42: 322-327. [Medline] [CrossRef]

31. Saito, S. and Taniguchi, K. 2000. Expression patterns of glycoconjugates in the three distinctive olfactory pathways of the clawed frog, Xenopus laevis. J. Vet. Med. Sci. 62: 153-159. [Medline] [CrossRef]

32. Sarnat, H. B. and Netsky, M. G. 1974. Evolution of the Nervous System. Oxford University Press, New York.

33. Scalia, F. and Winans, S. S. 1975. The differential projections of the olfactory bulb and accessory olfactory bulb in mammals. $J$. Comp. Neurol. 161: 31-55. [Medline] [CrossRef]

34. Soeta, S., Izu, Y., Saito, T. R., Yamano, S. and Taniguchi, K. 2005. Differential expression of neurofilament 200-like immunoreactivity in the main olfactory and vomeronasal systems of the Japanese newt, Cynopus pyrrhogaster. J. Vet. Med. Sci. 67: 701-706. [Medline] [CrossRef]

35. Suzuki, K., Taniguchi, K. and Syuto, B. 1999. Characterization of olfactory receptor organs in Xenopus laevis Daudin. Anat. Rec. 255: 420-427. [Medline] [CrossRef]

36. Takami, S. and Graziadei, P. P. C. 1991. Light microscopic Golgi study of mitral/tufted cells in the accessory olfactory bulb of the adult rat. J. Comp. Neurol. 311: 65-83. [Medline] [CrossRef]

37. Takami, S. and Hirosawa, K. 1990. Electron microscopic observations on the vomeronasal sensory epithelium of a crotaline snake, Trimeresurus flavoviridis. J. Morphol. 205: 45-61. [CrossRef]

38. Taniguchi, K., Arai, T. and Ogawa, K. 1993. Fine structure of the septal olfactory organ of Masera and its associated gland in the golden hamster. J. Vet. Med. Sci. 55: 107-116. [Medline] [CrossRef]

39. Taniguchi, K., Matsusaki, Y., Ogawa, K. and Saito, T. R. 1992. Fine structure of the vomeronasal organ in the common marmo- set (Callithrix jacchus). Folia Primatol. (Basel) 59: 169-176. [Medline] [CrossRef]

40. Taniguchi, K. and Mikami, S. 1985. Fine structure of the epithelia of the vomeronasal organ of horse and cattle. A comparative study. Cell Tissue Res. 240: 41-48. [Medline] [CrossRef]

41. Taniguchi, K., Saito, S., Oikawa, T. and Taniguchi, K. 2008. Phylogenic aspects of the amphibian dual olfactory system. $J$. Vet. Med. Sci. 70: 1-9. [Medline] [CrossRef]

42. Taniguchi, K., Saito, S. and Taniguchi, K. 2011. Phylogenic outline of the olfactory system in vertebrates. J. Vet. Med. Sci. 73: 139-147. [Medline] [CrossRef]

43. Theisen, B. 1972. Ultrastructure of the olfactory epithelium in the Australian lungfish Neoceratodus forsteri. Acta Zool. 53: 205-218. [CrossRef]

44. Thornhill, R. A. 1967. The ultrastructure of the olfactory epithelium of the lamprey Lampetra fluviatilis. J. Cell Sci. 2: 591-602. [Medline]

45. Wilson, J. A. F. and Westerman, R. A. 1967. The fine structure of the olfactory mucosa and nerves in the teleost Carassius carassius L. Z. Zellforsch. Mikrosk. Anat. 83: 196-206. [Medline] [CrossRef]

46. Wysocki, C. J. 1979. Neurobehavioral evidence for the involvement of the vomeronasal system in mammalian reproduction. Neurosci. Biobehav. Rev. 3: 301-341. [Medline] [CrossRef]

47. Yamamoto, Y., Mori, M., Saito, S., Amano, M., Yamanome, T., Taniguchi, K., Oikawa, T., Yamamori, K. and Taniguchi, K. 2004. Differential expression of histochemical characteristics in the developing olfactory receptor cells in a flatfish, barfin flounder (Verasper moseri). J. Vet. Med. Sci. 66: 1609-1611. [Medline] [CrossRef]

48. Yokosuka, M., Hagiwara, A., Saito, T. R., Aoyama, M., Ichikawa, M. and Sugita, S. 2009. Morphological and histochemical study of the nasal cavity and fused olfactory bulb of the browneared bulbul, Hysipetes amaurotis. Zoolog. Sci. 26: 713-721. [Medline] [CrossRef]

49. Zeiske, E. and Melinkat, R. 1976. Ultrastructure studies on the epithelia of the olfactory organ of cyprinodonts (Teleostei, Cyprinodontoidea). Cell Tissue Res. 172: 245-267. [Medline] [CrossRef] 